\title{
DEMOGRAPHIC FEATURES OF PEDIATRIC B-ALL (B LINEAGE ACUTE LYMPHOBLASTIC LEUKEMIA) PATIENTS IN PAKISTANI POPULATION.
}

\footnotetext{
1. MBBS, M.Phil (Hematology) Senior Demonstrator Hematology University of Health Sciences, Lahore.

2. MBBS, M.Phil

Medical Officer Hematology University of Health Sciences, Lahore.

3. MBBS, FCPS

Assistant Professor Immunology Children Hospital and Institute of Child Health, Lahore.

4. MBBS, FCPS

HOD Hematology

University of Health Sciences,

Lahore.
}

Correspondence Address:

Dr. Moizza Sahar

Department of Hematology

University of Health Sciences, Lahore.

moizzahassan@live.com

Article received on:

01/10/2019

Accepted for publication:

$25 / 01 / 2020$

\section{Moizza Sahar ${ }^{1}$, Saira Gul'2, Farhana Shehzad ${ }^{3}$, Shahida Mohsin ${ }^{4}$}

ABSTRACT... Objectives: This study was conducted to evaluate demographic features of pediatric B-ALL patients in Pakistani population and their prognosis in a Tertiary Care Hospital. Study Design: Descriptive study. Setting: Department of Pathology Tertiary Care Children Hospital, Lahore. Period: $1^{\text {st }}$ January 2016 to $31^{\text {st }}$ December 2016. Material \& Methods: A total of 66 samples of newly diagnosed B-ALL patients (aged 1-15 years) were taken for study. For diagnosis of B-ALL, bone marrow aspiration, cytochemical staining, immunophenotyping was done. Results: Out of 66 B-ALL patients, 35 (53\%) were males and 31 (47\%) were females. The median age for pediatric ALL subjects was 5 years. Out of 66 B-ALL patients, 39 (59\%) were in standard risk group. The prognosis of ALL patients in our study was poor as compared with international statistics with $12 / 21$ deaths (57\%) in standard risk group. Also, history of consanguinity of parents was significantly high in dead patients $(p=0.013)$. Deaths were also comparatively more in males than in females. Conclusion: The prognosis of pediatric B-ALL patients in our study was poor as compared with international statistics because of multifactorial reasons. Strategies are needed to be adopted to improve the outcome of B-ALL patients in our population.

Key words: $\quad$ B-ALL, B Lineage Acute Lymphoblastic Leukemia, LDH: Lactate Dehydrogenase, TLC: Total Leucocyte Count.

Article Citation: Sahar M, Gul S, Shehzad F, Mohsin S. Demographic features of pediatric B-ALL (B Lineage Acute Lymphoblastic Leukemia) patients in Pakistani population. Professional Med J 2020; 27(8):1582-1589.

DOI: 10.29309/TPMJ/2020.27.08.4206

\section{INTRODUCTION}

Acute lymphoblastic leukemia is the most common leukemia accounting for $26 \%$ of all cancer incidences in children. ${ }^{1}$ ALL incidence peaks in children aged 2 to 5 years. ${ }^{2}$ In the US, each year 2000-2500 new cases of childhood ALL are diagnosed. ${ }^{3} \mathrm{ALL}$ is more common in boys than in girls, also the male gender is associated with poor prognosis. ${ }^{4}$ Acute Lymphoblastic Leukemia accounts for one third of total registered cases of childhood cancer in Pakistani population. ${ }^{5}$

The National Cancer Institute $\mathrm{NCl}$ criteria divide B-ALL patients into standard and high-risk categories. Children between 1 and 9 years of age and white blood cell (WBC) count of $<50 \mathrm{x}$ $10^{9} / \mathrm{L}$ fall into the standard risk category. Children older than 10 years and WBC count of $>50 x$ $109 / \mathrm{L}$ are categorized as high-risk.
The prognosis of high risk group is poor as compared to the standard risk group, so the high risk group have intensive treatment strategies.

Globally, the cure rate of childhood ALL is above $80 \% .{ }^{6}$ Multiple factors, genetics as well as environmental are involved in the development of ALL. Due to better diagnosis and improved treatment, the survival rate of childhood ALL patients has considerably improved worldwide and also in Pakistan. ${ }^{7}$

There are only a few studies related to demographics and prognosis of pediatric B-ALL in Pakistan. The current study was aimed at identifying the clinical presentations, laboratory diagnosis and the outcome of children diagnosed with B-ALL. Though a single-centre study, it will serve as a platform for future studies and also facilitate to improve the factors associated with 
poor outcome.

\section{OBJECTIVE}

This study was conducted to determine the demographic features of pediatric B-ALL patients in Pakistani population and their outcome.

\section{MATERIAL \& METHODS}

The present study was conducted on 66 B-ALL samples after approval of synopsis from ethical review committee of University of Health Sciences and Tertiary Health Care Hospital, Lahore. The study period was one year from $1^{\text {st }}$ January 2016 to $31^{\text {st }}$ December 2016. History and written consent were taken from the parents of patients. Newly diagnosed cases of B-ALL (aged 1-15 years) on basis of clinical presentation, morphology, cytochemistry and immunophenotyping were selected for the study. Non probability purposive sampling was done. It was a descriptive study.

A minimum $1 \mathrm{ml}$ of blood and bone marrow aspirate samples were taken in EDTA vacutainer and analyzed on BD FACS Canto $^{\text {TM }} \|$ flow cytometer using BD FACS Canto ${ }^{\mathrm{TM}}$ clinical and Diva software. Immunophenotyping was done on gated blast cells using an extensive panel of antibodies including myeloid markers (CD13, CD33 and cytoplasmic antiMPO) and lymphoid markers (CD34, CD2, CD3, CD5, CD7, CD4, CD8, HLA DR, CD10, CD19, CD22; cytoplasmic CD3, CD22, CD79a and nuclear antiTdT). All monoclonal antibodies were purchased from BD biosciences; San Jose, CA (Figure-1).

The data was entered and analyzed by using SPSS version 20. Frequencies, percentages and Chi-square test were used for qualitative variable. For quantitative variables, Shapiro Wilk test was used to differentiate parametric data from nonparametric data. The mean $\pm S D$ and student t-test were used for parametric data. Median and IQR, Man-Witney $U$ test and Kruskal Wallis test were used for non-parametric data. P-value of 0.05 was considered significant.

\section{RESULTS}

We evaluated 66 samples of B-lineage ALL patients out of which 35 (53\%) were males while
$31(47 \%)$ were females. The patients were divided into two age groups. Majority of the patients were $<10$ years $(85 \%)$. While 10 patients $(15 \%)$ were $\geq$ 10 years. The median age of ALL patients was 60 months (range $=12-180$ months). Consanguinity of parents was present in majority of the patients (60\%). Fever was the most common presenting complaint at the time of diagnosis (94\%). Almost half of the patients presented with bleeding tendency that included bruising, epistaxis or bleeding from any part of the body (45\%). On general physical examination (GPE), out of 66 patients, lymphadenopathy was present in 41 (62\%) patients while hepatomegaly in 60 (91\%) pateints and splenomegaly in 50 (76\%) patients (Table-I).

\begin{tabular}{|c|c|c|c|}
\hline Variable & Description & Frequency & Percentage \\
\hline \multirow{2}{*}{ Age } & $<120$ months & 56 & $85 \%$ \\
\hline & >121months & 10 & $15 \%$ \\
\hline \multirow{2}{*}{ Gender } & Male & 35 & $53 \%$ \\
\hline & Female & 31 & $47 \%$ \\
\hline \multirow{2}{*}{$\begin{array}{l}\text { Consanguinity } \\
\text { of parents }\end{array}$} & Present & 40 & $61 \%$ \\
\hline & Absent & 26 & $39 \%$ \\
\hline \multirow{2}{*}{$\begin{array}{l}\text { Bruising/ } \\
\text { Bleeding }\end{array}$} & Present & 30 & $45 \%$ \\
\hline & Absent & 36 & $55 \%$ \\
\hline \multirow{2}{*}{ Fever } & Present & 62 & $94 \%$ \\
\hline & Absent & 4 & $6 \%$ \\
\hline \multirow{2}{*}{$\begin{array}{l}\text { Lymphadeno- } \\
\text { pathy }\end{array}$} & Present & 41 & $62 \%$ \\
\hline & Absent & 25 & $38 \%$ \\
\hline \multirow{2}{*}{ Hepatomegaly } & Present & 60 & $91 \%$ \\
\hline & Absent & 6 & $9 \%$ \\
\hline \multirow[t]{2}{*}{ Splenomegaly } & Present & 50 & $76 \%$ \\
\hline & Absent & 16 & $24 \%$ \\
\hline Table-I. D & $\begin{array}{l}\text { graphic featur } \\
\qquad(n=66) .\end{array}$ & of ALL & ents \\
\hline
\end{tabular}

\begin{tabular}{|c|c|c|c|}
\hline Parameter & Description & Frequency & Percentage \\
\hline \multirow{2}{*}{$\begin{array}{l}\text { Hemoglobin } \\
\text { (g/dl) }\end{array}$} & $\leq 10$ & 55 & $83 \%$ \\
\hline & $>10$ & 11 & $17 \%$ \\
\hline \multirow{3}{*}{$\begin{array}{l}\text { WBC count } \\
\left(\times 10^{9} / \mathrm{l}\right)\end{array}$} & $\leq 4.5$ & 16 & $24 \%$ \\
\hline & $4.6-49$ & 32 & $49 \%$ \\
\hline & $\geq 50$ & 18 & $27 \%$ \\
\hline \multirow{2}{*}{$\begin{array}{l}\text { Platelet count } \\
\left(\times 10^{9} / \mathrm{I}\right)\end{array}$} & $\leq 50$ & 34 & $52 \%$ \\
\hline & $>50$ & 32 & $48 \%$ \\
\hline
\end{tabular}

Table-II. Laboratory findings of ALL patients $(n=66)$. 


\begin{tabular}{|c|c|c|c|}
\hline Parameter & $\begin{array}{l}\text { Morphological } \\
\text { remission } \\
(n=24)\end{array}$ & $\begin{array}{c}\text { No } \\
\text { morphological } \\
\text { remission } \\
(n=19) \\
\text { Mean } \pm \text { SD }\end{array}$ & $\begin{array}{l}\text { Early Death } \\
\quad(n=16)\end{array}$ \\
\hline Blast \% & $\begin{array}{c}62.50 \pm \\
27.12\end{array}$ & $\begin{array}{c}61.37 \pm \\
30.25\end{array}$ & $\begin{array}{c}75.81 \pm \\
22.3\end{array}$ \\
\hline $\begin{array}{l}\text { Hemoglobin } \\
\text { (g/dl) }\end{array}$ & $7.10 \pm 2.85$ & $7.67 \pm 2.46$ & $\begin{array}{c}8.41 \pm \\
3.36\end{array}$ \\
\hline $\begin{array}{l}\text { Serum LDH } \\
(\mathrm{U} / \mathrm{L})\end{array}$ & $\begin{array}{l}986 \pm \\
1029.2\end{array}$ & $\begin{array}{c}775.5 \pm \\
631\end{array}$ & $\begin{array}{c}1180 \pm \\
1018\end{array}$ \\
\hline $\begin{array}{l}\text { TLC count } \\
\left(\times 10^{9} / 1\right)\end{array}$ & $33.61 \pm 49$ & $\begin{array}{c}34.89 \pm \\
61.26\end{array}$ & $\begin{array}{c}48.61 \pm \\
55.79\end{array}$ \\
\hline $\begin{array}{l}\text { Platelet } \\
\text { count }\left(\times 10^{9} / \mathrm{I}\right)\end{array}$ & $78.1 \pm 77.6$ & $\begin{array}{c}75.21 \pm \\
67.46\end{array}$ & $\begin{array}{c}81.46 \pm \\
109\end{array}$ \\
\hline
\end{tabular}
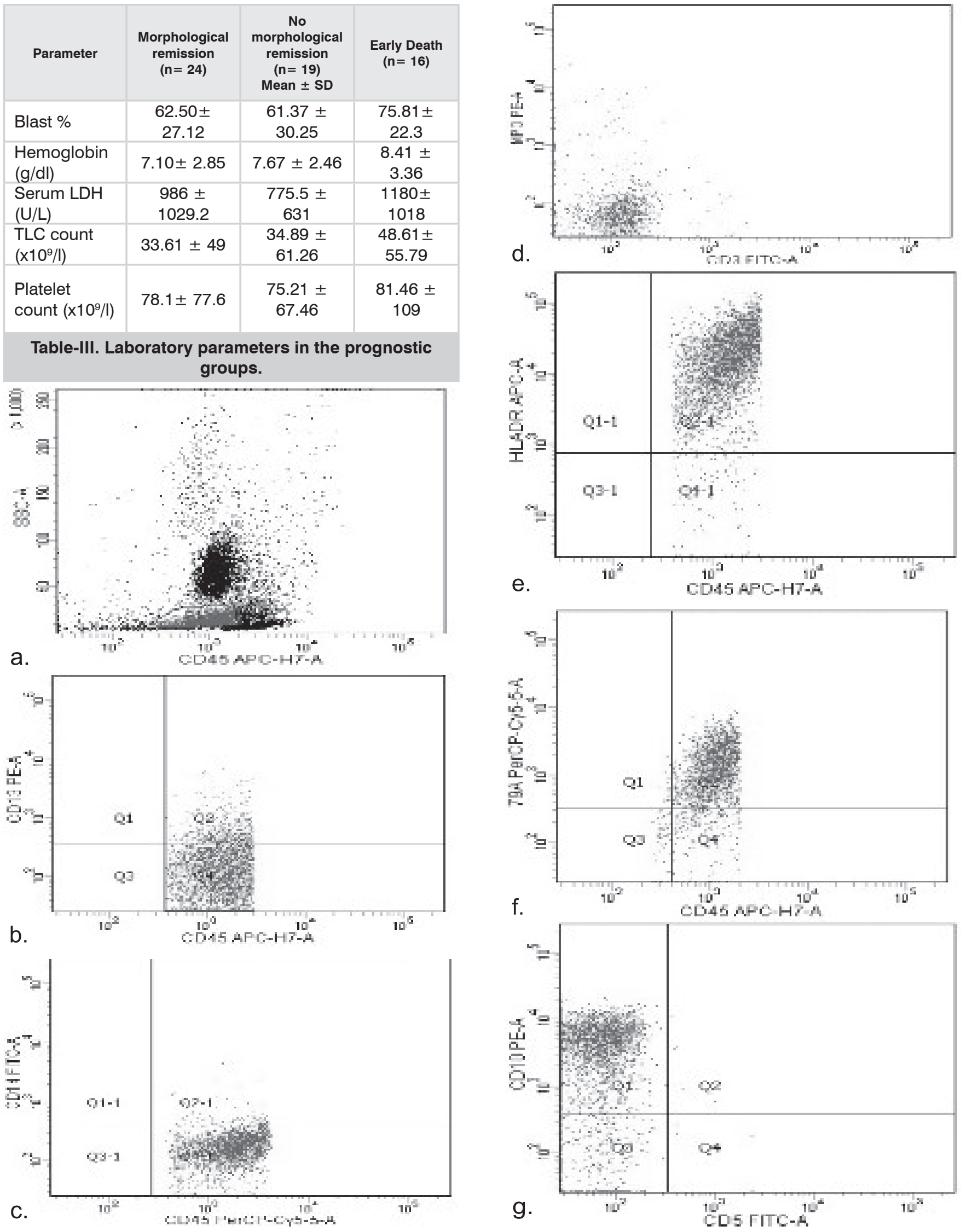

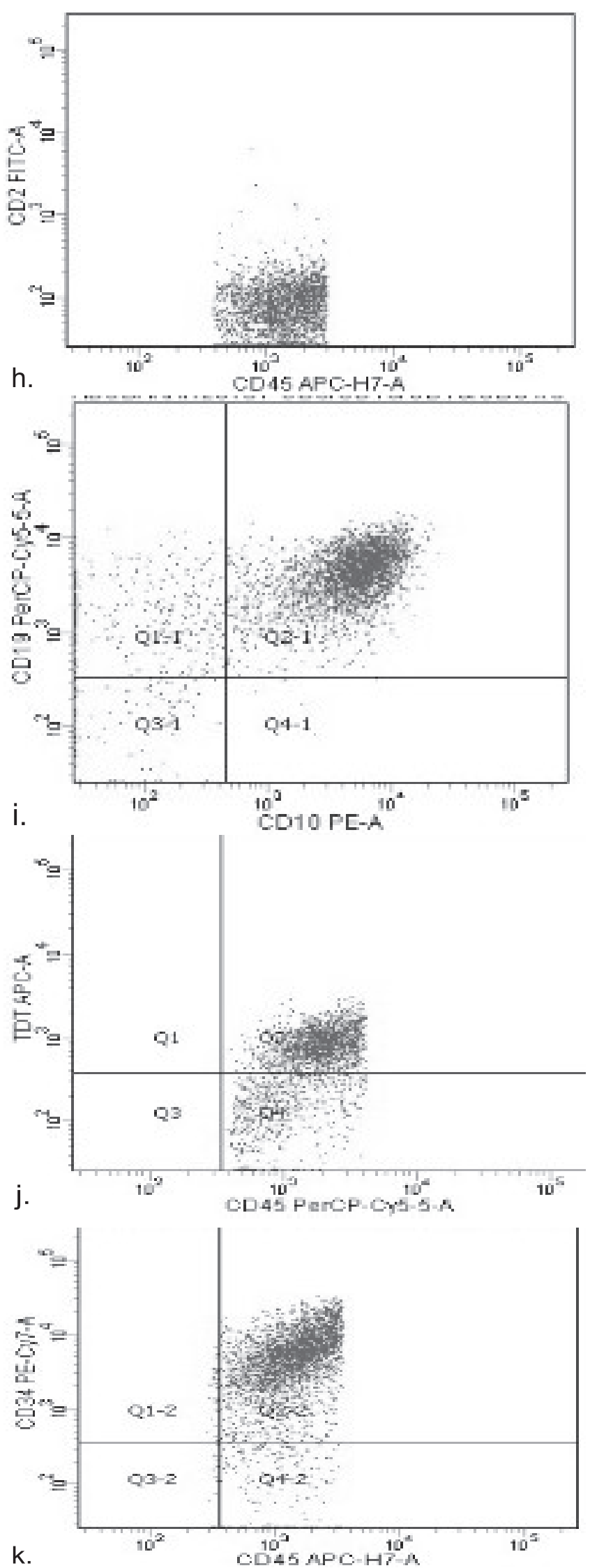

Figure- 2.1: Diagnosis of a case of pre B-ALL (ID no.20).

a. CD 45 (leucocyte common antigen) was used for gating and a gate was established around the lymphoblast area (P1). The lymphoblast show low SSC (due to low intracellular complexity).

b, c and d. CD 13, CD 14 and myeloperoxidase (MPO) were negative $(14.8 \%, 4.7 \%$ and $2.2 \%$ respectively). So, the myeloid lineage of the blasts was ruled out.

e, $\mathbf{f}$ and $\mathbf{g}$. Expression of surface marker HLA DR (76.9\%) and Cytoplasmic CD 79a (85.6\%) confirms B-lineage of blasts. B lymphoblast characteristically express high CD 10 (88.5\%) with negative CD 5.

h. CD 2 is negative so $T$ lineage of ALL is ruled out.

i, Pre B ALL blasts characteristically co express CD 10 (88.5\%) and CD 19 (87.8\%).

j and $\mathbf{k}$ Expression of TdT (72.6\%) and CD $34(87.8 \%)$ indicating immaturity is also characteristically seen in pre B-ALL.

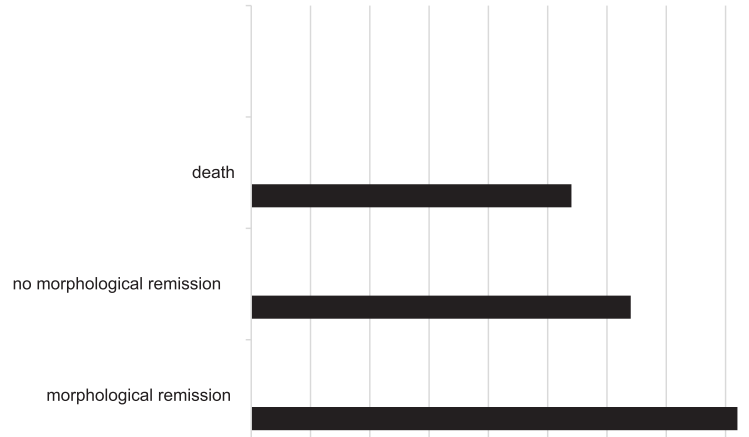

$0.00 \% \quad 5.00 \% 10.00 \% 15.00 \% 20.00 \% 25.00 \% 30.00 \% 35.00 \% 40.00 \% 45.00 \%$

Figure-2. Bar chart representing prognosis of ALL patients at day 28 of induction therapy. Out of 66 B-ALL patients, 7 patients were lost to follow up. In the remaining 59 patients, $24(41 \%)$ patients achieved morphological remission on day 28 bone marrow, while $19(32 \%)$ patients did not achieve remission and $16(27 \%)$ patients had early death during induction therapy.

Laboratory findings of ALL patients $(n=66)$ The all patients were divided into groups according to ranges of their hemoglobin, TLC count and 
patelet count. The hemoglobin in all patients ranged from 2.4- 15.3g/dl (mean $=7.79 \pm 2.84 \mathrm{~g} /$ dl). About $83 \%$ of patients were anaemic at the time of diagnosis and had hemoglobin $\leq 10 \mathrm{~g} / \mathrm{dl}$. The mean hemoglobin level was almost equal in both genders. In males, mean hemoglobin was $7.71 \pm 2.78 \mathrm{~g} / \mathrm{dl}(2.8-15.3 \mathrm{~g} / \mathrm{dl})$ while in females, the mean hemoglobin was $7.82 \pm 3.07 \mathrm{~g} / \mathrm{dl}(2.5$ $13.8 \mathrm{~g} / \mathrm{dl})$.

WBC count of the patients varied from leucocytosis with TLC $\geq 50 \times 10^{9} /$ to leucopenia (TLC $\leq 4.5$ $\left.\mathrm{x} 10^{9} / \mathrm{l}\right)$. Its range was $0.8-233.50 \times 10^{9} / \mathrm{l}$ (mean $=$ $\left.40.24 \pm 52.52 \times 10^{9} / 1\right)$. The WBC count in females was $52.84 \pm 59.39 \times 10^{9} / \mathrm{l}$ ranging from $0.8 \times 10^{9} / \mathrm{I}$ to $232.60 \times 10^{9} / \mathrm{l}$. While in males, the mean WBC count was $29.07 \pm 43.44 \times 10^{9} / \mathrm{l}$ ranging from 2.0 to $233.5 \times 10^{9} / 1$. Thirty four patients presented with thrombocytopenia at the time of diagnosis with platelet count below $50 \times 10^{9} / \mathrm{I}(52 \%)$. The platelet count ranged from $1-401 \times 10^{9} /$ I (mean 78.79 $\left.\pm 82.90 \times 10^{9} / \mathrm{l}\right)$. In males, the platelet count was $80.25 \pm 87.79 \times 10^{9} / /\left(1-401 \times 10^{9} / I\right)$. In females, the platelet count was $77.14 \pm 78.43 \times 10^{9} / /(3-$ $\left.318 \times 10^{9} / \mathrm{I}\right)$. The mean blast percentage in ALL patients was $66 \pm 26.66 \%$ (range $=10-98 \%$ ). Median value for blast percentage was $80 \%$ in ALL patients (Table-II).

The all patients were categorised into high risk and standard risk group according to National Cancer Institute $(\mathrm{NCl})$ criteria. High risk group included those patients with WBC count $\geq 50 \mathrm{x}$ $10^{9} / \mathrm{l}$ and age $\geq 10$ years. The standard risk group included the patients with WBC count $<50 \times 10^{9} / 1$ and age $<10$ years. Out of 66 B-ALL patients, 39 were in standard risk group, 1 patient was in high risk group while the remaining 26 patients did not fulfill the $\mathrm{NCl}$ criteria of classification in any of the groups.

\section{Prognosis of ALL patients on day 28 of induction therapy}

Follow up of ALL patients was done for a duration of 6 months and 07/66 B-ALL patients were lost to follow up. In the remaining 59/66 ALL patients, three prognostic groups were made after the day $28^{\text {th }}$ of induction therapy; Patients having blasts $<5 \%$ on bone marrow were considered to be in morphological remission; patients having blasts $>5 \%$ on bone marrow were considered not having morphological remission; and patients with early death (who died during induction therapy). Morphological remission was attained by $24 / 59$ (41\%) patients achieved, 19/59 (32\%) patients did not achieve remission and 16/59 (27\%) patients had early death (Figure-2).

\section{Laboratory parameters in the prognostic groups}

Blast percentage, serum LDH level and TLC count were highest in the dead patients. The laboratory parameters in the three prognostic groups are shown in Table-III.

\section{Prognosis of ALL patients after 6 months follow up}

After a further 6 months follow up of these 59 patients, the death toll increased from 16 to 21 . The cause of death of these patients included renal failure, liver failure, septic shock, drug toxicity and cardiac arrest. The remaining 36/59 (60\%) patients were on maintenance therapy who had minor complaints of intermittent infections and fever. Only $2 / 59$ (4\%) patients left the treatment.

\section{Prognosis of high/standard risk patients}

Out of 39 standard risk patients, 15/39 (38\%) patients achieved remission after day 28 of induction therapy, 12/39 (31\%) did not achieve remission, 10/39 (26\%) patients had early death and 2/39 (5\%) patient died during further 6 months follow up period. There was only 1 high risk patient and he attained remission.

The deaths were comparatively higher in males than in females, out of 21 died patients, 12 (57\%) were males and 9 (43\%) were females. Also, deaths were significantly more in patients having history of consanguinity of parents $(81 \%)(p=$ 0.013).

\section{DISCUSSION}

The current study was conducted on a total of 66 B-ALL patients. Out of 66 B-ALL patients, 35 (53\%) were males and 31 (47\%) were females. Worldwide, ALL is more common in males than in females. According to International Classification 
of Childhood Cancer (ICCC), 1.9/100,000 males and $1.5 / 100,000$ females are affected by ALL. ${ }^{8}$ Our data showed similar male preponderance in incidence of ALL. In present study, the median age for pediatric ALL subjects was 5 years. This finding was comparable to another Pakistani study which showed median age of 6 years. $^{9}$ However, according to National Cancer Institute, the median age at the time of diagnosis of ALL is 15 years in U.S.A. ${ }^{10}$ Majority of patients in our study were less than 5 years old (53\%). This can be explained because incidence of ALL peaks between ages 2 to 5 years. ${ }^{11}$

Many patients (94\%) in our study presented with fever at the time of diagnosis. The bruising/ bleeding tendency was seen in $45 \%$ of our study patients. This finding goes hand in hand with a previous study that showed fever and bruising at presentation in $81 \%$ and $46.3 \%$ of ALL patients respectively. ${ }^{12}$ In current study subjects, the mean hemoglobin level of ALL patients was 7.79 \pm $2.84 \mathrm{~g} / \mathrm{dl}$. This value was nearest to another study which shows the mean hemoglobin level of $8.0 \mathrm{~g} /$ dl in ALL patients. ${ }^{13}$

In present study, 39 (59\%) ALL patients were in standard risk group. This finding was nearly consistent with another study where $62.2 \%$ patients were in standard risk group. ${ }^{14}$

The prognosis of ALL patients in our study was poor as compared with international statistics. According to National Cancer Intelligence Network (NCIN), the survival rate of pediatric ALL is $90 \%$. The suboptimal outcome of our pediatric ALL patients can be explained by the socioeconomic status of the patients, lack of parental education, late diagnosis of disease, malnourishment and failure to control infections as stressed by another study on Pakistani population. ${ }^{15}$ Another Pakistani study has shown mortality rate of $24 \%$ in childhood ALL cases (74/304 patients). The main cause of death in these patients was infection. ${ }^{16}$ Contrary to these results, Idris et al. showed better prognosis of ALL with complete remission in $94 \%$ patients after induction therapy and with no mortality. ${ }^{17}$
Out of a total of 21 deaths in 6 months, 12/21 deaths $(57 \%)$ were in standard risk group. The findings by Hunger at el. has shown $36 \%$ deaths in standard risk group of ALL and emphasized the need for efforts to improve the survival in standard risk group along with efforts to improve survival in high risk group. ${ }^{18}$ Our findings call for similar efforts to improve survival in our setting as well.

Among 21 dead patients, 17/21 (81\%) had history of consanguinity of parents. So, consanguinity of parents was significantly high in dead patients $(p=0.013)$. This finding was consistent with those of Nasir et al, that showed similar high incidence of leukemia in children born to people having cousin marriages. ${ }^{19}$ The deaths were comparatively more in males than in females as stressed by earlier studies. ${ }^{20}$

\section{CONCLUSION}

ALL is more common in males than in females. The median age for pediatric ALL subjects was 5 years. Fever and bruising/bleeding tendency were the presenting complain in majority of the patients. The prognosis of ALL patients in our study was poor as compared with international statistics with $12 / 21$ deaths (57\%) in standard risk group. Also, 17/21 (81\%) deaths were in patients with history of consanguinity of parents $(p=$ 0.013). Deaths were also comparatively more in males than in females.

\section{Acknowledgment}

The authors would like to thank Dr. Nisar Ahmad, Professor of Pathology Department and Mr. Khalid Mahmood, Senior Medical Technologist, Children Hospital and Institute of Child Health, Lahore for the help and support.

Copyright $(25$ Jan, 2020.

\section{REFERENCES}

1. Morra ME, Kien ND, Elmaraezy A, Abdelaziz OAM, Elsayed $A L$, Halhouli $O$, et al. Early vaccination protects against childhood leukemia: A systematic review and meta-analysis. Scientific reports. 2017; $7(1): 15986$. 
2. Steliarova-Foucher E, Colombet M, Ries LA, Moreno $F$, Dolya $A$, Bray $F$, et al. International incidence of childhood cancer, 2001-10: A population-based registry study. The Lancet Oncology. 2017; 18(6):71931.

3. Phillips SM, Padgett LS, Leisenring WM, Stratton KK, Bishop K, Krull KR, et al. Survivors of childhood cancer in the United States: Prevalence and burden of morbidity. Cancer Epidemiology and Prevention Biomarkers. 2015; 24(4):653-63.

4. Haavisto A, Henriksson M, Heikkinen R, Puukko Viertomies LR, Jahnukainen $K$. Sexual function in male long $\square$ term survivors of childhood acute lymphoblastic leukemia. Cancer. 2016; 122(14):226876.

5. Yasmeen N, Ashraf S. Childhood acute lymphoblastic leukaemia; Epidemiology and clinicopathological features. JPMA. 2009; 59(150).

6. Pui $\mathrm{C}-\mathrm{H}$, Robison LL, Look AT. Acute Iymphoblastic leukaemia. The Lancet. 2008; 371(9617):1030-43.

7. Idris M, Farid J, Sarwar J, Ahmed S, Wiqar MA, Badsha S. Response rate of Pakistani children with acute lymphoblastic leukaemia to Medical Research Council acute lymphoblastic leukaemia 97 chemotherapy protocol. J Ayub Med Coll Abbottabad. 2010; 22(3).

8. Ward E, DeSantis C, Robbins A, Kohler B, Jemal A. Childhood and adolescent cancer statistics, 2014. CA Cancer J Clin. 2014; 64(2):83-103.

9. Fadoo Z, Nisar I, Yousuf F, Lakhani LS, Ashraf S, Imam $U$, et al. Clinical features and induction outcome of childhood acute lymphoblastic leukemia in a lower/ middle income population: A multi-institutional report from Pakistan. Pediatric blood \& cancer. 2015; 62(10):1700-8.

10. Howlader N, Noone A, Krapcho M, Miller D, Bishop $\mathrm{K}$, Altekruse S, et al. SEER cancer statistics review. National Cancer Institute. 2016: 1975-2013.

11. Inaba H, Greaves $M$, Mullighan CG. Acute lymphoblastic leukaemia. The Lancet. 2013; 381(9881):1943-55.

12. Mushtaq N, Fadoo Z, Naqvi A. Childhood acute lymphoblastic leukaemia: Experience from a single tertiary care facility of Pakistan. J Pak Med Assoc. 2013; 63(11):1399-404.
13. Teuffel O, Stanulla M, Cario G, Ludwig WD, Rottgers S, Schafer BW, et al. Anemia and survival in childhood acute lymphoblastic leukemia. Haematologica. 2008; 93(11):1652-7.

14. Ghali HH. Effectiveness of Modified UKALL protocols in Children with Acute Lymphoblastic Leukemia; an experience of Children Welfare Teaching Hospital: Council of Pediatrics in Partial Fulfillment of the requirement for the degree of Clinical HematoOncology subspecialty of the Iraqi Board for Medical Specializations in Pediatrics By Hasanein Habeeb Ghali MBChB-FIBMS-DCH Supervised by Salma A. Al-Hadad Professor College of Medicine, University of Baghdad; 2012.

15. Jabeen K, Ashraf MS, Iftikhar S, Belgaumi AF. The impact of socioeconomic factors on the outcome of childhood acute lymphoblastic leukemia (ALL) treatment in a low/middle income country (LMIC). Journal of pediatric hematology/oncology. 2016; 38(8):587-96.

16. Asim M, Zaidi A, Ghafoor T, Qureshi Y. Death analysis of childhood acute lymphoblastic leukaemia; Experience at Shaukat Khanum Memorial Cancer Hospital and Research Centre, Pakistan. JPMAJournal of the Pakistan Medical Association. 2011; $61(7): 666$.

17. Idris M, Farid J, Sarwar J, Ahmed S, Wiqar MA, Badsha $\mathrm{S}$. Response rate of Pakistani children with acute Iymphoblastic leukaemia to medical research council acute lymphoblastic leukaemia 97 chemotherapy protocol. Journal of Ayub Medical College Abbottabad. 2010; 22(3):8-11.

18. Hunger SP, Lu X, Devidas M, Camitta BM, Gaynon PS, Winick NJ, et al. Improved survival for children and adolescents with acute lymphoblastic leukemia between 1990 and 2005: A report from the children's oncology group. Journal of Clinical Oncology. 2012; 30(14):1663-9.

19. Nasir M, Jabeen F, Hussain SM, Shaheen T, Samiullah K, Chaudhry AS. Impact of consanguinity, environment, socio-economic and other risk factors on epidemiology of Leukemia. Pakistan Journal of Zoology. 2015; 47(4).

20. Sousa DWLd, Ferreira FVdA, Félix FHC, Lopes $\mathrm{MVdO}$. Acute Iymphoblastic leukemia in children and adolescents: Prognostic factors and analysis of survival. Revista brasileira de hematologia e hemoterapia. 2015; 37(4):223-9. 


\begin{tabular}{|c|c|c|c|}
\hline \multicolumn{4}{|c|}{ AUTHORSHIP AND CONTRIBUTION DECLARATION } \\
\hline Sr. \# & Author(s) Full Name & Contribution to the paper & Author(s) Signature \\
\hline 1 & Moizza Sahar & Principal investigator. & \\
\hline 2 & Saira Gul & Helped in article writing and & \\
\hline 3 & Farhana Shehzad & Helped in practical work. & \\
\hline 4 & Shahida Mohsin & Investigator. & \\
\hline
\end{tabular}

